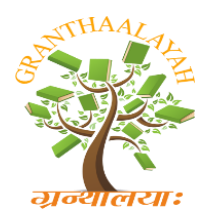
\author{
GRANTHAALAYAH \\ A knowledge Repository
}

INTERNATIONAL JOURNAL OF RESEARCH -

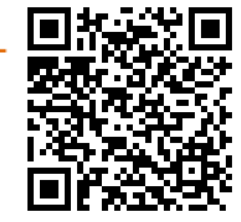

Science

\title{
MECHANICAL BEHAVIORS OF BANANA AND SISAL HYBRID COMPOSITES REINFORCED WITH EPOXY RESIN
}

\author{
Hemant Patel ${ }^{1}$, Prof. Ashish Parkhe ${ }^{2}$, Dr P.K. Shrama ${ }^{3}$ \\ ${ }^{1}$ PG Student, Department of Mechanical Engineering, Nri Institute of Information Science \& \\ Technology, Bhopal (M.P.), INDIA \\ 2, 3 Associate Professor, Department of Mechanical Engineering, Nri Institute of Information \\ Science \& Technology, Bhopal (M.P.), INDIA
}

\begin{abstract}
Natural fibers have been used to reinforce materials for over 200 years. The aim of this study is to evaluate mechanical properties such as tensile and flexural properties of hybrid banana and sisal reinforced epoxy composites they have been employed in combination with plastics. Natural fibers like as hemp, jute, sisal and banana. It's have the advantage that they are renewable resources and have marketing appeal these agricultural wastes can be used to prepare fiber The composites have many advantages over traditional glass fiber and inorganic materials. In this paper, test are conducted for composite material constitutes banana and less discovered sisal These composites are adhered using epoxy resin consists resin and hardener suitably mixed in appropriate volume Here for preparing samples Hand layup method is used, specimens are prepared and tests are carried out, which shows tensile and bending strengths. The tensile \& compressive tests were applied on specimens of $300 \times 50 \times 10 \mathrm{~mm}$ in dimensions but in different proportions of banana and sisal by weight.
\end{abstract}

Keywords:

Bio-degradability, banana; composites, sisal, resin.

Cite This Article: Hemant Patel, Prof. Ashish Parkhe, and Dr P.K. Shrama, "MECHANICAL BEHAVIORS OF BANANA AND SISAL HYBRID COMPOSITES REINFORCED WITH EPOXY RESIN" International Journal of Research - Granthaalayah, Vol. 4, No. 1 (2016): 206216.

\section{INTRODUCTION}

Natural fibers have appeared to be the materials which will become a feasible replacement for non-renewable, abrasive and expensive synthetic fibers during recent years, mainly due to their availability in large quantities, biodegradability, low cost, low density, recyclability and ease of manufacturing them "Beghezan defines as - The composites are compound materials which differ from alloys by the fact that the individual components retain their characteristics but are so incorporated into the composite as to take advantage only of their attributes and not of their short 
comings, in order to obtain improved materials" A Biomaterial is a non-viable material used in medical device, so it's intended to interact with biological systems. Requirements of Biomaterials are It must be inert or specifically interactive. It must be Biocompatible. Mechanically and chemically stable. Biodegradable Process able (manufacturability): It must be machinable, and moldable. Sterilizable, non-toxic, non-allergenic, blood compatible, noninflammatory. Physical Characteristics Requirements: Strength, Toughness, Elasticity, Corrosion-resistance, Wear resistance, Long term stability Natural fibers are a major renewable resource material throughout the world specifically in the tropics. According to the food and agricultural organization survey, natural fibers like jute, sisal, coir, banana, etc. are abundantly available in developing countries. Natural fibers are an attractive research area because they are eco-friendly, inexpensive, Abundant and renewable, lightweight, low density, high toughness, high specific properties, biodegradability and non-abrasive to processing characteristics, Therefore, natural fibers can serve as reinforcements by improving the strength and stiffness and also by reducing the weight of the resulting bio composite materials although the properties of natural fibers vary with their source and treatments. A Bio-material is defined as any systemically, pharmacologically inert substance or combination of substances utilized for implantation within or incorporation with a living system to supplement or replace functions of living tissues or organs. Biomaterial devices used in orthopedics are commonly called implants; these are manufactured for a great number of orthopedic applications The use of natural fibers reduce the $10 \%$ of weight and lower energy used with production by $80 \%$ and while the cost of component 5\% lower than the comparable fiber glass reinforced component. A key factor driving the increased applications of composites over the recent years is the development of new advanced forms of fiber reinforced materials. Fiber reinforced composites are lightweight, nocorrosive, exhibit good specific strength and good stiffness, are easily constructed, and can be tailored to satisfy performance requirements. Apart from these characteristics natural fibers are still expensive today as compare to traditional materials because of less demand of products manufactured from these fiber materials because of less knowledge of these fibers applications

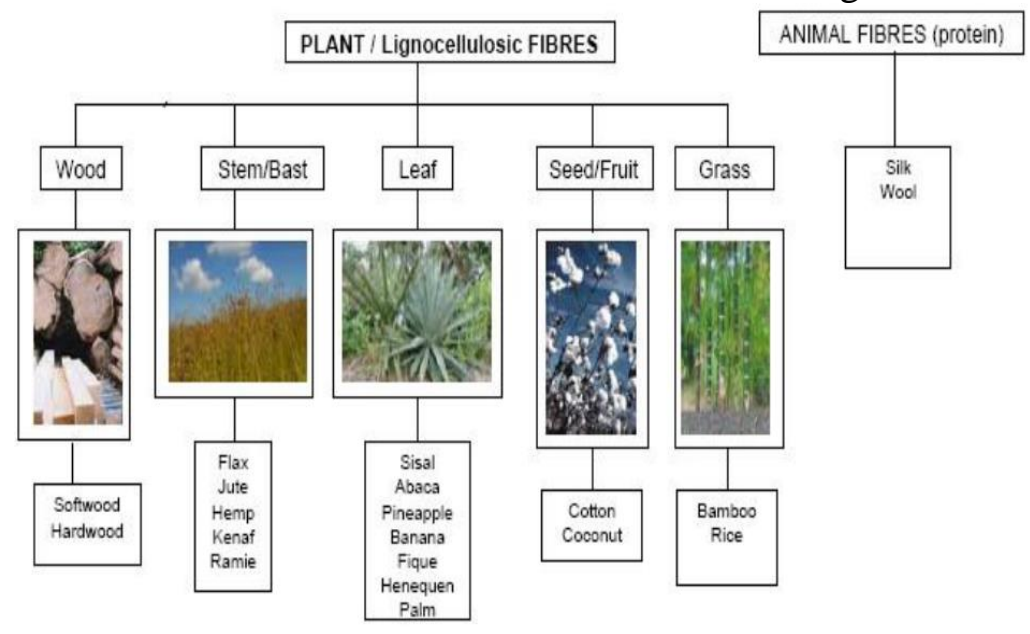

Figure 1: Classification of fibers

Banana is only by hand-scraping that good quality fibers are produced. Banana plant is a large perennial herb with leaf sheaths that form pseudo stem. Its height can be 10-40 feet (3.0-12.2 meters) surrounding with 8-12 large leaves. This source of fibers provides great strength. Historically, banana fiber was extraction by hand. 
This work pertains to utilization of the Banana fiber developed from the stem of Banana tree. After harvesting the ripe Banana fruits, the tree becomes use less and is thrown away Banana fiber is an important agricultural product. It is one of the most common natural fibers in Third World countries such as India, China, Bangladesh, etc. The banana fiber has special importance in the economy of India and continues to be a major traditional earner of foreign exchange. However, it is facing tough competition from the synthetic fibers. Banana fibers find use in sophisticated fields like decorative and furnishing materials such as lamp shades, wall covers, curtains, upholsteries, etc

Sisal is a natural fiber is a yield, stiff fiber traditionally used in making twine and rope. It is a biodegradable and eco-friendly crop. Moreover, sisal is a strong, stable and versatile material and it has been recognized as an important source of fiber for composites. Sisal fiber made from the large spear shaped tropical leaves of the Agave Sisalana plant. Sisal fiber is extracted by a process known as decortications, where leaves are crushed and beaten by a rotating wheel set with blunt knives, so that only fibers remain. Now Sisal has been utilized as an environmentally friendly strengthening agent to replace asbestos and fiberglass in composite materials in various uses including the automobile industry.

\section{LITERATURE SURVEY}

(M.Ramesh et al K.Palanikumar K.Hemachandra Reddy/ 2013 /Comparative Evaluation on Properties of Hybrid Glass Fiber- Sisal/Jute Reinforced Epoxy Composites/ science direct) The aim of this study is to evaluate mechanical properties such as tensile and flexural properties of hybrid glass fiber-sisal/jute reinforced epoxy composites Scanning electron microscope (SEM) analysis is carried out to evaluate fiber matrix interfaces and analyze the structure of the fractured surfaces (1). The commercial Finite Element Analysis software ANSYS is used for numerical study. (M. Ramesh et al T.Sri Ananda Atreyaa, U. S. Aswina, H. Eashwara, C. Deepab/2014/Processing and Mechanical Property Evaluation of Banana Fiber Reinforced Polymer Composites) In the fast developing world, the concern for the environmental pollution and the prevention of non-renewable and non-biodegradable resources has attracted researchers seeking to develop new eco-friendly materials and products based on sustainability principles.(2) (Vishnu Prasada et al Ajil Joya, G. Venkatachalama, S.Narayanana, S.Rajakumarb/2014/Finite Element analysis of jute and banana fibre reinforced hybrid polymer matrix composite and optimization of design parameters using ANOVA technique) In this work, an investigation is carried out on jute fiber, a natural fiber The test is performed on the Universal Testing Machine (UTM) and the surrounding temperature is $35^{\circ} \mathrm{C}$. A tensile test specimen placing in the testing machine and applying load until it fractures (3) (R. Bhoopathia et al M. Ramesha,*, C. Deepab/2014/Fabrication and Property Evaluation of Banana-Hemp-Glass Fiber Reinforced Composites) The main objective of this experimental study is to fabricate the banana-hemp-glass fibers reinforced hybrid composites and to evaluate the mechanical properties such as tensile strength, flexural strength and impact strength. The specimen is prepared according to ASTM standards and the experiment has been carried out by using universal testing machine (UTM) (4). 
Table 1: Properties of Sisal and Banana Fiber

\begin{tabular}{|l|l|l|}
\hline PROPERTY NAME & Sisal & Banana \\
\hline Width or Diameter (mm ) & $50-200$ & $80-250$ \\
\hline Density (gm./cc) & 1.45 & 1.35 \\
\hline Cellulose/Lignin Content (\%) & $67 / 12$ & $65 / 5$ \\
\hline Elastic Modulus (GN/m2) & $9-16$ & $8-20$ \\
\hline Tenacity (MN/m2) & $568-640$ & $529-754$ \\
& & \\
\hline Elongation (\%) & $3-7$ & $1-3.5$ \\
\hline Tensile strength (Mpa) & 54 & 68 \\
\hline Flexural modulus (Gpa) & 2.5 & $12.5-17.5$ \\
\hline
\end{tabular}

\section{EXPERIMENT DETAILS}

\subsection{MATERIALS}

Sisal fiber is a natural fiber of Agavaceae (Agave) family a type of leaf fiber is extracted from sisal plant leaves used for making ropes and twine. Banana fiber comes from family name (Musaceac) family a type of bast fiber, extracted from banana tree. Epoxy resin and hardner is used as a reinforcement material.

\subsection{BANANA FIBER EXTRACTION}

Mature banana pseudo-stem was obtained from farm and was cut into length of $500 \mathrm{~mm}$ shied longitudinally into four pieces and each was totally submerged in water for 15 days The stems from banana plants (Musa paradisiaca) were selected from an 11-month-old plantation. The plantation is located 1,050 meters above sea level, has $22.5^{\circ} \mathrm{C}$ average temperature, $76 \%$ relative humidity, $2.100 \mathrm{~mm}$ annual rainfall, 6.1 $\mathrm{PH}$ and 2,010 hours annual sunshine .The extracted fibers were then treated with $5 \%$ sodium hydroxide $(\mathrm{NAOH})$ solution for four hour .After this wash tap water until natural PH is attained. The treated fiber were dried in an oven for 24 hours at $105^{\circ} \mathrm{C}$ in order to removed free water, then cut to required dimension .The properties of banana fiber are given in Table 1.

\subsection{SISAL FIBER EXTRACTION}

Sisal leaves was obtained from farm and was cut into length of $500 \mathrm{~mm}$ sliced longitudinally and were chopped and cleaned using a benzene-ethanol in a 2:1 liquid ratio by volume. Fiber were soaked in (NAOH) solution of desired while heated at $80{ }^{\circ} \mathrm{C}$ stirred for 90 minutes .Washed with distilled water to $\mathrm{PH}$ value 6 and then dried under vacuum at $60{ }^{\circ} \mathrm{C}$ to remove free water and cut to required dimensions and stored in a tight container The properties of sisal fiber are given Table 1. 


\subsection{PREPARATION OF EPOXY RESIN}

Epoxy resin density of $1.15-1.20 \mathrm{~g} / \mathrm{cm}^{3}$, mixed with hardener density of $0.97-0.99 \mathrm{~g} / \mathrm{cm}^{3}$, is used to prepared the composite material resin from purchased local source

\subsection{PATTERN}

The pattern is designed by as per ASTM standard. The pattern is made up of mild steel. The pattern Size is 235 × 85 × $15 \mathrm{~mm}$ (ASTM D37-08) The pattern consist of three parts

- Base Plate

- Frame

- Lid

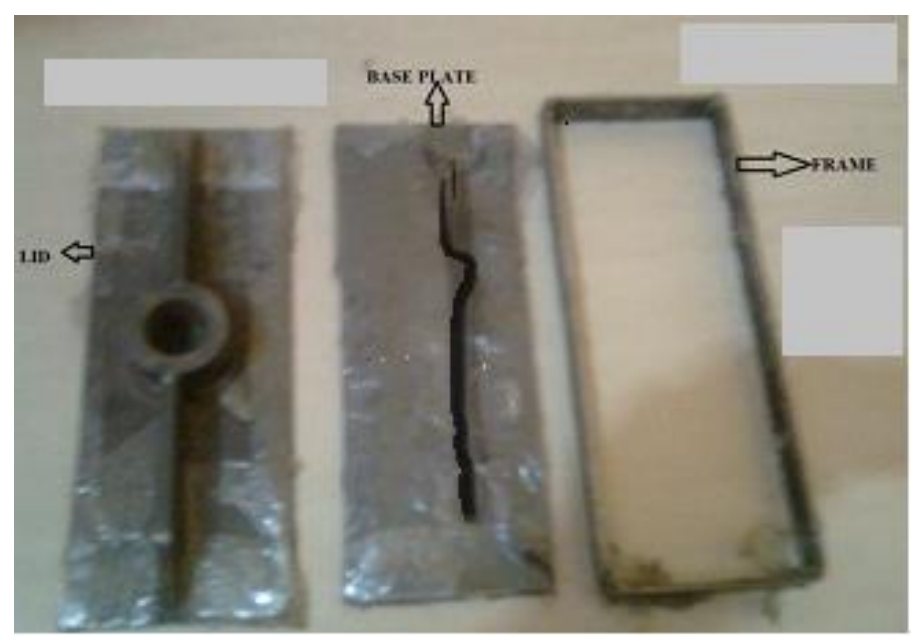

Figure 2: Pattern

\subsection{MOULD PREPARATION}

In mould preparation the resin is mixed with hardener in the ratio of $4: 1$. The mixer is strewed with stirrer for 15 minutes continuously

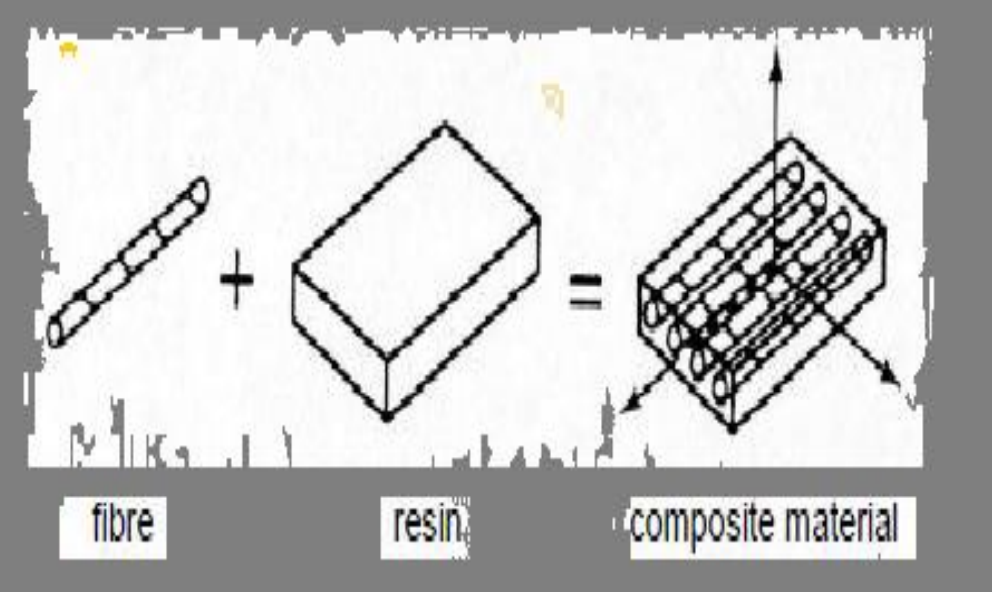

Figure 3: Mold Preparation 


\section{TEST RESULTS\& DISCUSSIONS}

Table 2: Impact, Hardness, Tensile, and Flexural Properties of Sisal and Banana Fiber

\begin{tabular}{|l|l|l|l|l|}
\hline Fiber & $\begin{array}{l}\text { Imp } \\
\text { act } \\
\text { Stre } \\
\text { ngth } \\
\text { (kj/ } \\
\left.\mathbf{m}^{3}\right)\end{array}$ & $\begin{array}{l}\text { Hardn } \\
\text { ess } \\
\text { Strengt } \\
\text { h } \\
\text { (Mpa) }\end{array}$ & $\begin{array}{l}\text { Tensile } \\
\text { Strengt } \\
\text { h } \\
\text { (Mpa) }\end{array}$ & $\begin{array}{l}\text { Flexur } \\
\text { al } \\
\text { modul } \\
\text { us }\end{array}$ \\
\hline Sisal & 1.1 & 102.23 & 59.7 & 26.4 \\
\hline Banana & 2.1 & 95.14 & 20 & 33.3 \\
\hline Sisal \& banana(20\%B,80\%S) & 3.02 & 97.45 & 60.06 & 30.4 \\
\hline Sisal \& banana(50\%B,50\%S) & 2.8 & 95.2 & 32.2 & 33.3 \\
\hline
\end{tabular}

On Basis: - (Taking 30g resin mix with hardener, Total weight of specimen: - 60g) 100B:- $100 \%$ Banana mix with 30g resin+ hardener. 80S20B:- $80 \%$ Sisal \& $30 \%$ banana mix with $30 \mathrm{~g}$ resin hardener. 50S50B:- 50\% Sisal \& 50\% banana mix with 30g resin+ hardener. 100S:- $100 \%$ Sisal mix with $30 \mathrm{~g}$ resin+ hardener.

\subsection{TENSILE TESTING}

Specimens were made to test tensile properties .The sample dimensions are:- Length- 300mm long, Wide- $50 \mathrm{~mm}$, Thick- $10 \mathrm{~mm}$. Separate specimen were made for each changed weight ratio of banana and Sisal in composite. In this tensile test weight of resin and hardener is kept fixed and ratio of sisal and banana fiber is varied in different fractions to see the variations in their behavior. While making specimen various precautions were taken for making the specimen in desired form Fibers of standard length are taken in desired weight for testing, while making the fiber should not break because if fiber breaks desired result will not be achieved. While applying resin and hardener hand gloves should be wear so that fiber will not stick to hands, after applying resin and hardener specimen should be immediately kept under mould and kept under suitable pressure up to 48 hours, 


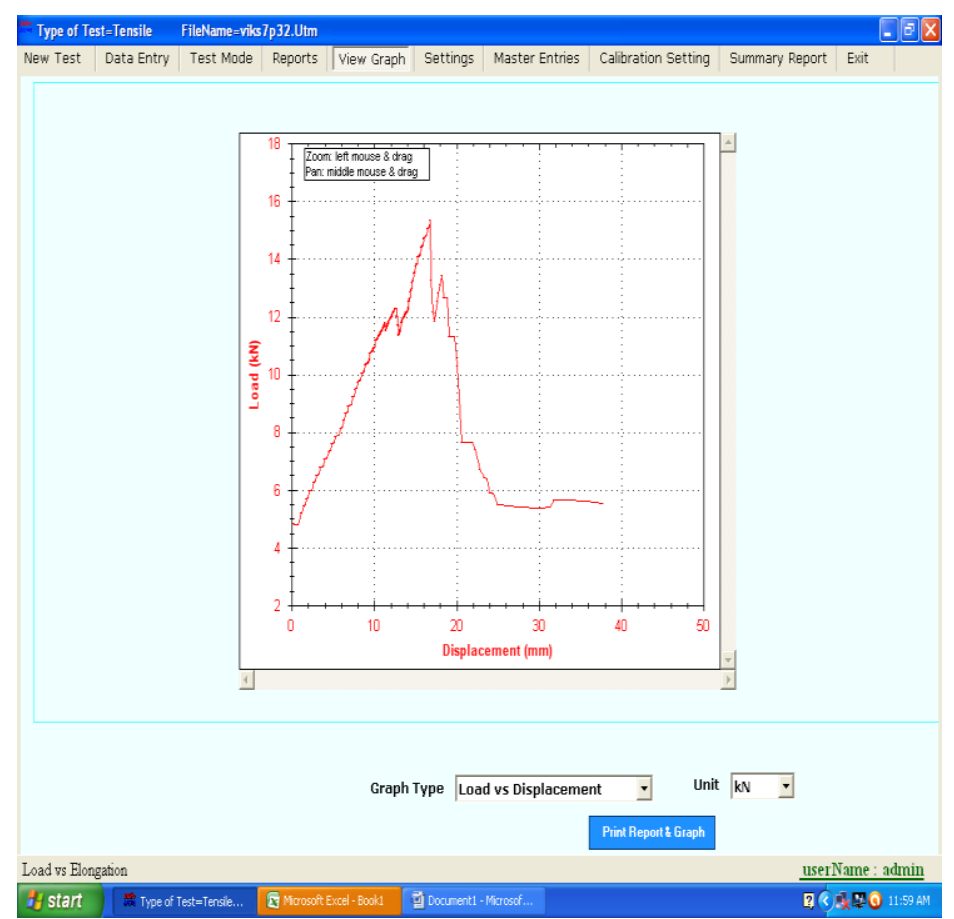

Tensile Test (Load vs Displacement)

\subsection{COMPRESSION TEST}

Single point compression bend test is performed on each specimen of different volume fractions of the composite.

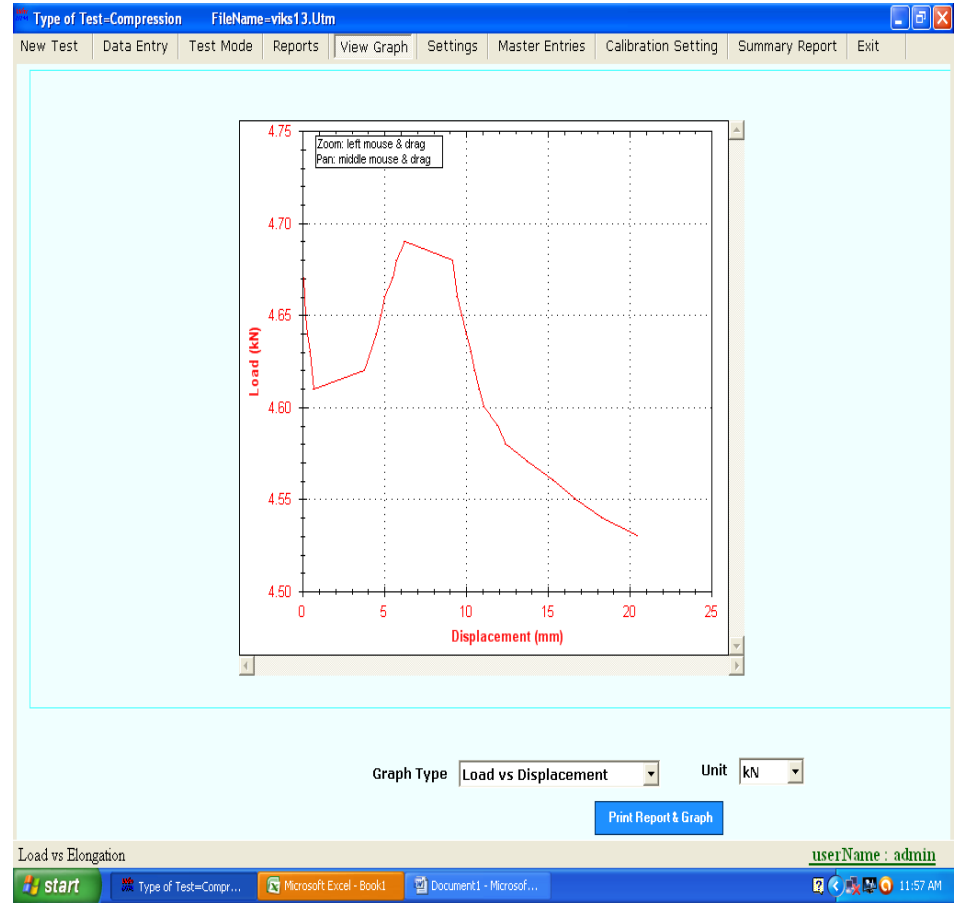

Compression Test (Load vs Dispacement) 


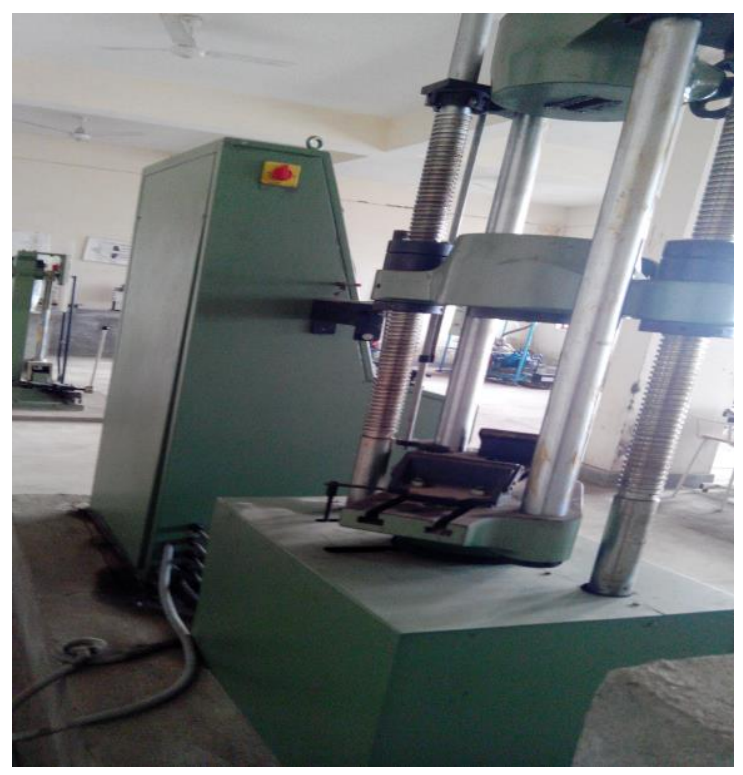

\subsection{IMPACT TESTING}

Figure 4: Compression Test in UTM

For impact testing specimens are prepared had following specifications:-

Length $-60 \mathrm{~mm}$

Wide:- $30 \mathrm{~mm}$.

Depth:- $10 \mathrm{~mm}$.

Charpy test methodology is used to test the impact properties of composite specimens. From the results it is evident that banana fiber gets the lowest impact strength whereas sisal got the good impact strength as compare to all the results. In this testing impact effect is tested and measurement is calculated in $\left(\mathbf{k j} / \mathbf{m}^{3}\right)$.

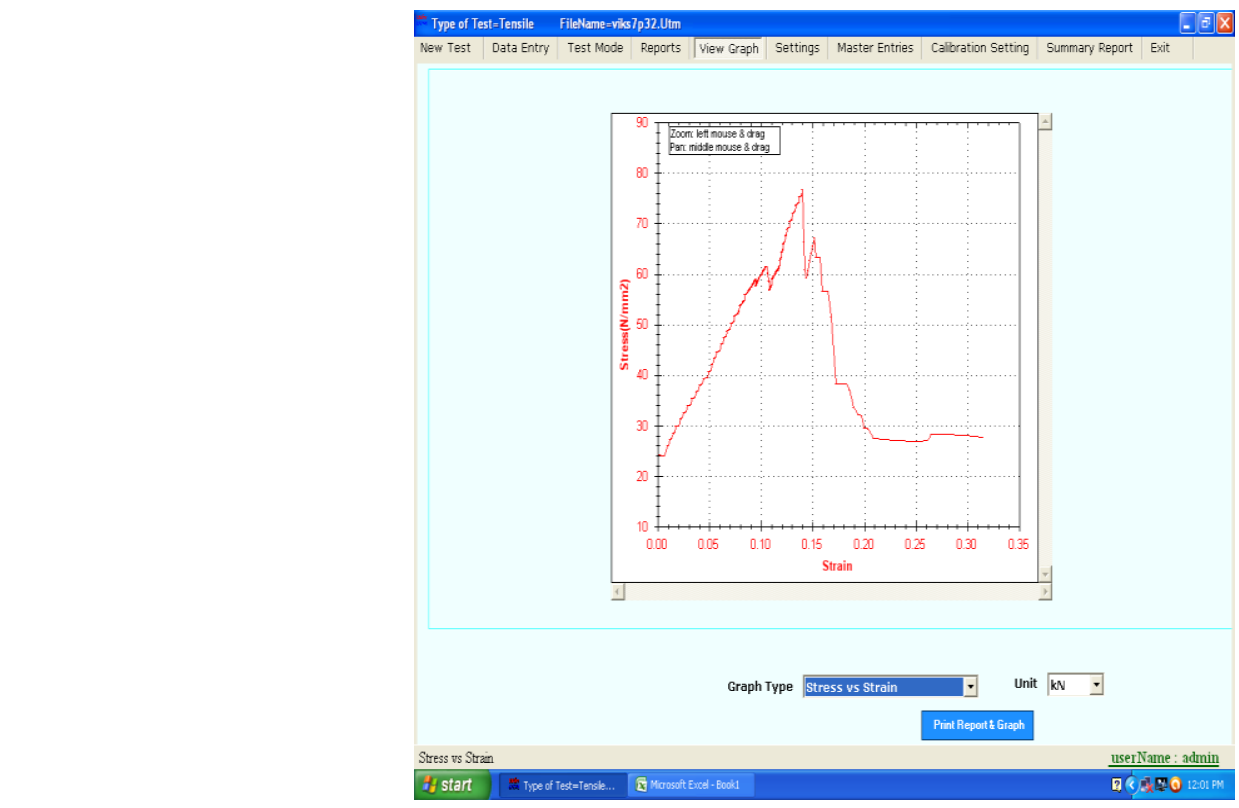

Sisal Fibre Tensile Graph 


\subsection{HARDNESS TEST RESULTS}

The Rockwell hardness number represents the additional depth to which a test ball or sphereconical penetrator is driven by a heavy (major) load beyond the depth of a previously applied light (minor) load. Top hardness numbers that are obtained from hard materials indicate a shallow indentation while low numbers found with soft materials indicate deep indentation. The increment of penetration depth for each point of hardness on the Rockwell mount is 0.00008 inch. For example, if a piece of steel measures Rockwell C 58 (extremely hard) at same point and C 55 at another, the depth of penetration would have been 0.00024 inch deeper at the softer spot.

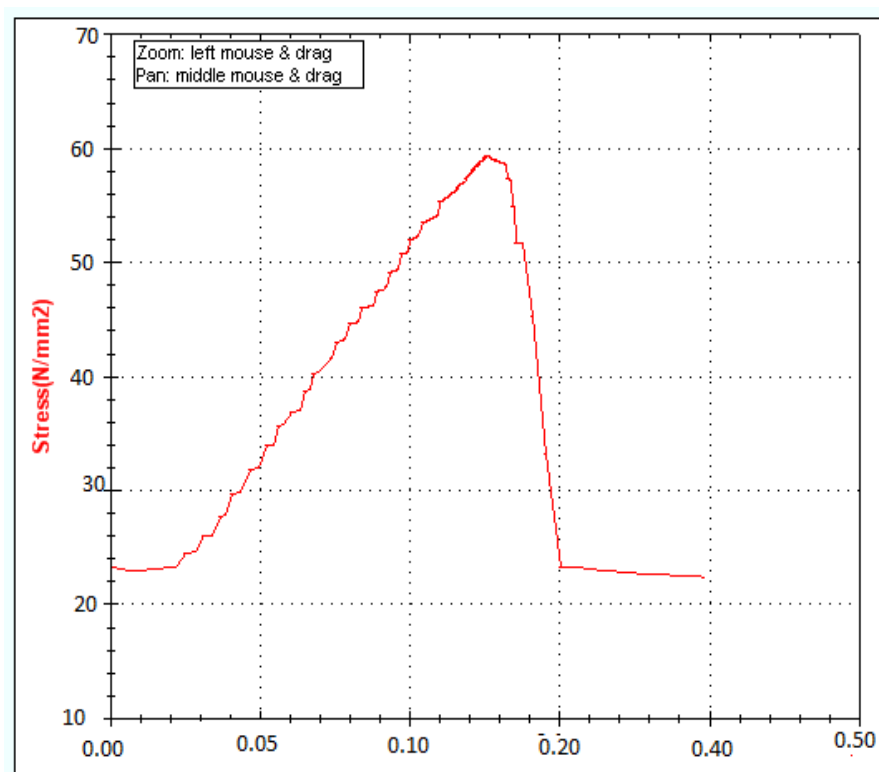

Banana Fiber Tensile Graph

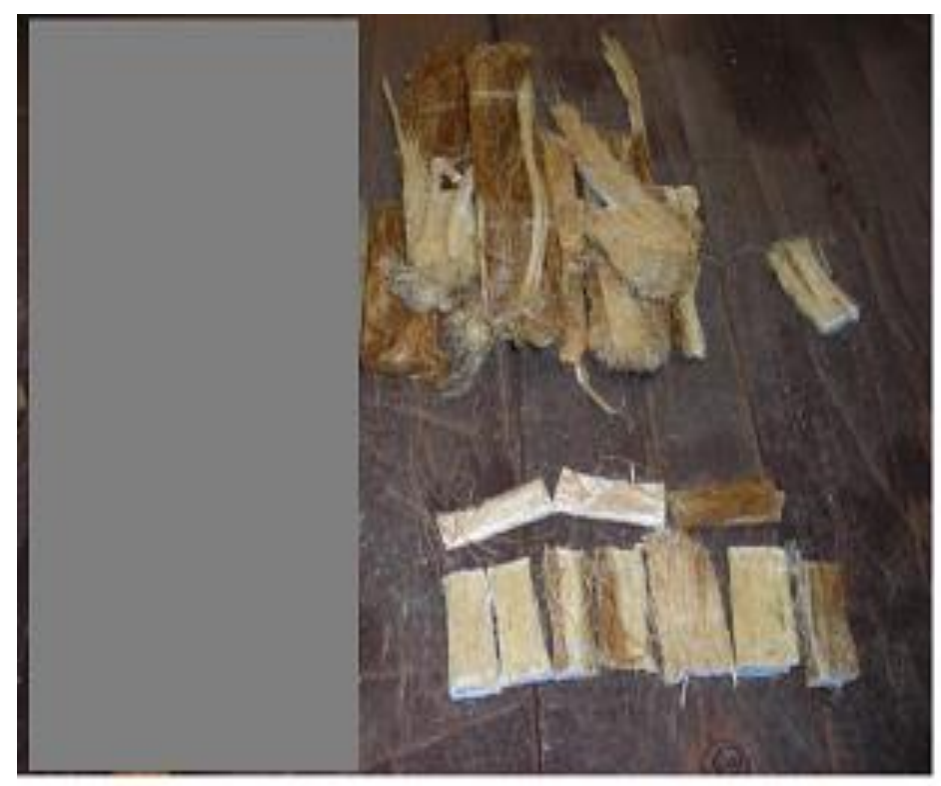

Figure 5: 


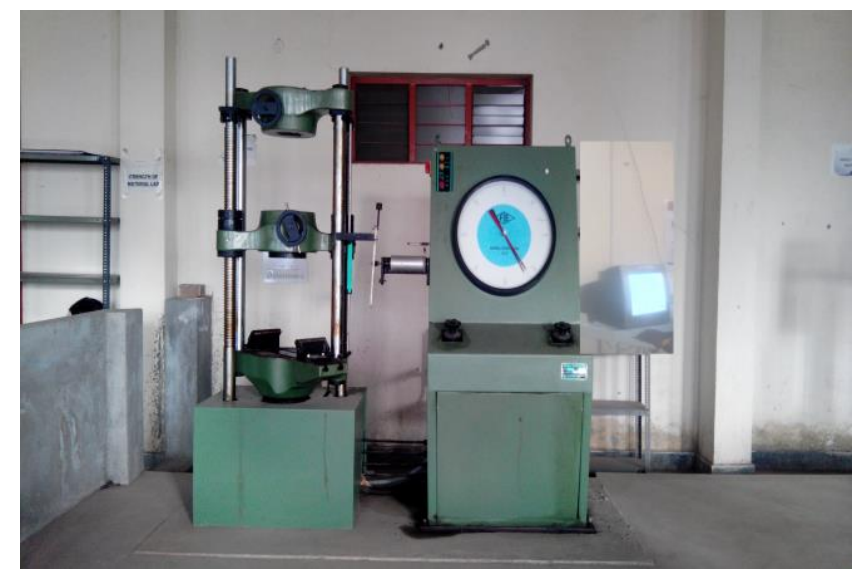

Figure 6:
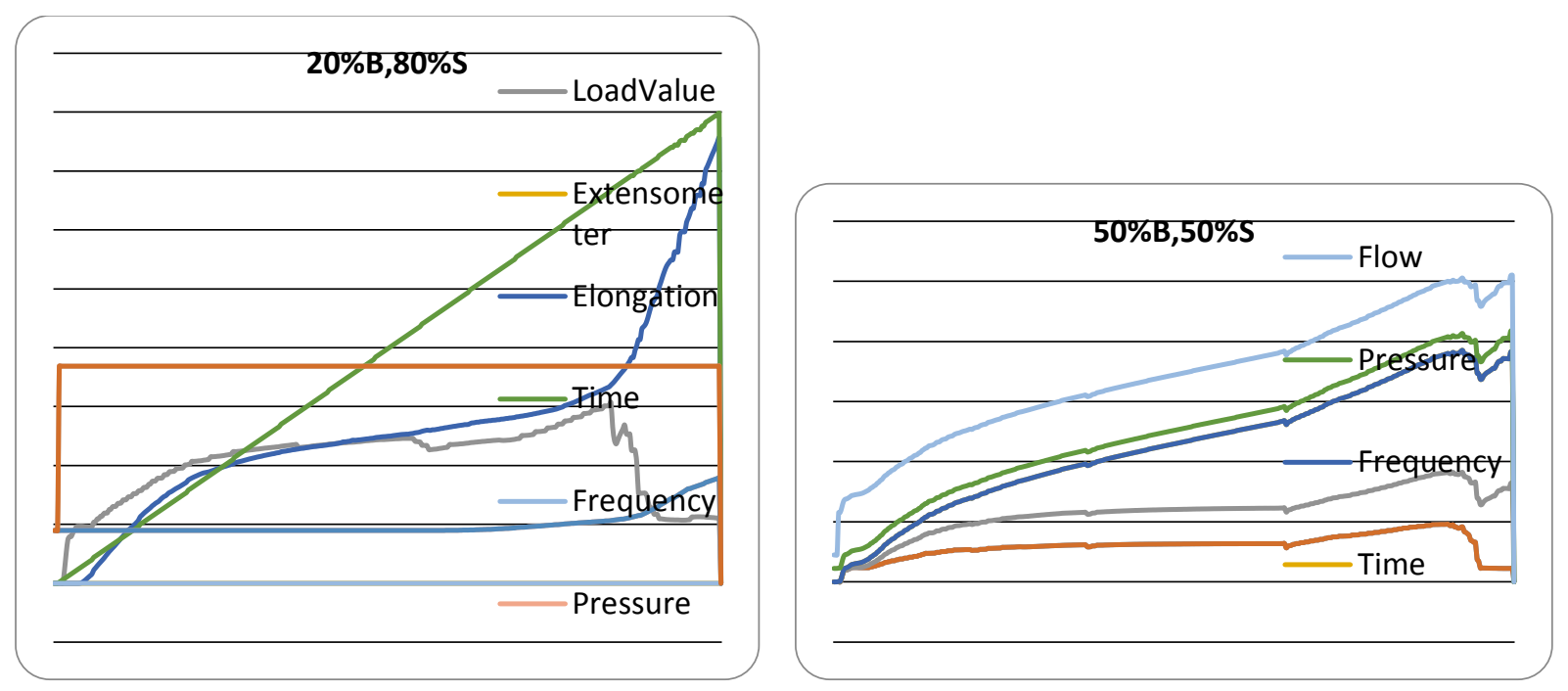

\section{CONCLUSION}

This experimental investigation of mechanical behavior of banana and sisal reinforced epoxy composites leads to the following conclusions:

- The mechanical properties will be change with change in composition of fibers.

- On combination of sisal and banana where banana is in excess amount than sisal tensile strength value is high but bending values are low.

- Sisal fiber individually had the highest tensile strength but low bending and impact strength so it should be mix with banana fiber to obtain the desired strength and mechanical properties.

- Increase in hardener ratio with epoxy resin mechanical properties will change and excessive hardener will lead towards brittleness of composite material.

- Composite made from 50\%Sisal and 50\% banana had less strength from composite having $80 \%$ Sisal and $20 \%$ banana fiber ratios.

- In this experiment the length of fibers are kept constant, if length variation takes place, properties also changes. 
- On application side, banana fiber is some extent used in automotive applications,

- As banana fiber is known for its remarkable smoothness its mixture with sisal fiber will lead towards better surface finish of the product with desired strength.

\section{REFERENCES}

[1] N. Venkateshwaran, A. ElayaPerumal, A. Alavudeen, M. Thiruchitrambalam, Mechanical and water absorption behaviour of banana/sisal reinforced hybrid composites, Materials and Design;2011;32:4017 4021.

[2] M.M. Kabir, H. Wang, K.T. Lau, F. Cardona, Chemical treatments on plant-based natural fibre reinforced polymer composites: An overview, Composites: Part B;2012;43: 28832892.

[3] Panthapulakkal S, Sain M., Injection-molded short hemp fiber/glass fiber reinforced polypropylene hybrid composites mechanical, water absorption and thermal properties, Applied Polymer Science;2007;103:2432 2441.

[4] Sathasivam K., Haris M.R.H.M., Noorsal K., The Preparation and Characterization of Esterified Banana Trunk Fibers/Poly(vinyl alcohol) Blend Film, Polymer-Plastics Technology and Engineering; 2010; 49(13): 1378-1384. DOI: 10.1080/03602559.2010.512324.

[5] Biswal M., Mohanty S., Nayak S.K., Effect of Mercerized Banana Fiber on the Mechanical and Morphological Characteristics of Organically Modified FiberReinforced Polypropylene Nanocomposites, Polymer-Plastics Technology and Engineering; 2011; 50(14):1458-1469. DOI: 10.1080/03602559.2011.593079.

[6] Naik J. B., Mishra S., Studies on Electrical Properties of Natural Fiber: HDPE Composites, Polymer-Plastics Technology and Engineering;2005; 44(4): 687-693. DOI: 10.1081/PTE-200057818

[7] Venkateshwaran N, Elayaperumal A, Sathiya GK, Prediction of tensile properties of hybrid-natural fiber composites. Composites: Part B;2012;43(2):793-796

[8] K.N. Indira, Jyotishkumar Parameswaranpillai, and Sabu Thomas, (2013) Mechanical properties \& Failure topography of banana fiber, Hindawi publishing corporation, ISRN Polymer science.

[9] 2. D. Chandramohan \&.K. Marimuthu,( 2011).A Review on natural fibers, IJRRAS 8(2). 